\title{
Awareness, Positivity of Pap Smear in Adult Females
}

\author{
J. C. Sharma ${ }^{1} \cdot$ Komal Leekha $^{1}$
}

Received: 13 April 2018/Revised: 16 June 2018/Accepted: 18 June 2018 / Published online: 16 July 2018

(C) The Author(s) 2018

\begin{abstract}
Introduction Cervical cancer is the fourth most common cancer in females worldwide. Every year estimated 528,000 new cases occur, out of which $85 \%$ cases are in developing countries. There were approximately 266,000 deaths for carcinoma cervix worldwide in 2012. The introduction of Papanicolaou (Pap) test led to significant reduction in mortality and morbidity. Lack of awareness, unwillingness for the test and non-availability of resources for undertaking Pap smear has taken a serious toll in prevention of cervical cancer which is the common gynaecological cancer in India.

Material and Method A cross-sectional study was conducted among 500 apparently healthy ladies between 21 and 65 years of age from northeast origin and from rest of India in study duration of 18 months. The study comprised of questionnaire analysis, health education by health worker and Pap smear examination. Data were statistically analysed and evaluated.

Result In the study only 23.6\% (118/500) of participants are aware of Pap smear out of which 95\% (113/118) says it is for early detection of cervical cancer. Time interval to repeat Pap smear in every 3 years is said by $53.4 \%(63 / 118)$ and best timing to do the test is 10 th to 20th days of menstrual cycle said by $38 \%$ (45/118). However, scoring of knowledge suggests only $22.88 \%$ (27/118) is having adequate knowledge, i.e. they have given correct answer to all the three questions. Participants who were aware of Pap smear (118) and undergone Pap smear themselves is statistically significant with $p$ value of 0.0001 . The study has detected normal smear (313) $75.06 \%$, infection (candida, trichomonas) (24) 5.75\%, inflammatory smear (7) $1.67 \%$, ASCUS (27) $6.47 \%$, LSIL (43) $10.3 \%$, HSIL (2) $0.48 \%$ and cervical cancer (1) $0.24 \%$. Conclusion Among participants only 58\% (69/118) were aware of Pap smear, and had ever done Pap smear and only $31 \%$ (37/118) ever recommended Pap smear to others, suggesting attitude towards practice of Pap smear is better compared to other studies. The Pap test has fairly good specificity in detection of cervical pathology in asymptomatic women.
\end{abstract}

Keywords Cancer cervix Awareness · Clinical utility $\cdot$ Pap smear $\cdot$ Adult female

\section{Introduction}

Cancer is a leading cause of death in females in age group of 35-65 years. Cervical cancer is the fourth most common cancer in females worldwide. Every year estimated 528,000 new cases occur, out of which $85 \%$ cases are in developing countries. There was approximately 266,000 deaths for carcinoma cervix worldwide in 2012 [1]. One in every five women in the world who is suffering from cervical cancer belongs to India which has the largest burden of cervical cancer patients in the world. The

\footnotetext{
$\bowtie$ J. C. Sharma

jcsharma47@ rediffmail.com

5 Air Force Hospital, Jorhat, Assam 785005, India
}

disproportionate increase in developing countries is due to lack of effective screening, diagnosis and limited treatment. It is possible to prevent deaths due to cervical cancer through various strategies that target women $>30$ year for screening and treatment [2].

The introduction of Papanicolaou (Pap) test led to significant reduction in mortality and morbidity. In several western countries where screening programme has been linked to effective treatment, cervical cancer rate has been decreased by as much as $65 \%$ [1]. On the other hand, the screening coverage in Asian countries is low and varies from 50 per cent in Singapore which has an existing Cancer Screening Programme to $2.6-5$ per cent in India [3-5]. Every year in India, 122,844 women are diagnosed with cervical cancer and 67,477 die from the disease [6]. India also has the highest age standardized incidence of cervical 
cancer in South Asia at 22, compared to 19.2 in Bangladesh, 13 in Sri Lanka and 2.8 in Iran. Therefore, it is vital to understand the epidemiology of cervical cancer in India.

In north east region of India incidence is 24.3 per 1 lac in Aziwal, 17.1 per lac in Mizoram, 11 per lac in Nagaland, 10.1 per lac in Arunachal Pradesh and 5.6 per lac in Dibrugarh [7].

Human papillomavirus (HPV) is a DNA virus that pass through skin-to-skin contact and sexual intercourse. HPV plays an important role in development of genital warts, cervical intraepithelial neoplasia (CIN). Depending on their oncogenic potential, HPV types are grouped into [8]: High oncogenic risk-Types 16, 18, 31, 33, 35, 45, 56 can lead to cervical cancer and are associated with other mucosal anogenital and head and neck cancers and low oncogenic risk-Types $6,11,42,43$ can cause benign or low-grade cervical tissue changes and genital warts (condyloma acuminata), which are growths on the cervix, vagina, vulva and anus in women and the penis, scrotum or anus in men. Over $99.7 \%$ of patients with CIN and invasive cancer are found to be positive with HPV DNA. The various risk factors for HPV infection are early marriage, early and multiple child birth, multiple sexual partners, low socioeconomic status, family history of cervical cancer, smoking, long-term use of oral contraceptives and immuno-compromised state [9].

Early HPV infections may be accompanied by mild changes in the epithelium that are detectable by screening using virological and/or cytological techniques like Pap smear. The Pap smear is a screening tool to detect early stages of cervical cancer. It has become a routine test performed during gynaecological care. Pap smear can detect infection, reactive cellular changes associated with inflammation, atrophic changes precancerous stage, squamous cell and glandular cells carcinomas. If a smear found to be abnormal, further test is done to determine whether HPV is present or not, which would increase the chances of diagnosis in woman developing cervical cancer. Several tests such as visual inspection with acetic acid (VIA), visual inspection with Lugol's iodine (VILI), colposcopyguided biopsy. HPV DNA test can also be used in screening of cervical cancer [10].

The awareness about cervical cancer, Pap smear is variable ranging from $90 \%$ in health workers like doctors, nursing staff to about $10-15 \%$ in general population. The aim of this study is to assess the awareness about Pap smear and clinical utility. Area covered is of Assam mainly Jorhat and nearby adjacent location. Population cover is families in defence area along with local residence of Jorhat, advantage of which is individuals from various part of India being covered at one location. This will spread awareness to a higher level and will be beneficial to mankind.

\section{Methodology}

With the objectives: to assess the awareness about Pap smear, to identify their attitude towards Pap smear and to assess specificity of Pap smear for detection of cervical cancer.

A cross-sectional study was conducted in the Department of Obstetrics and Gynaecology, 5 Air Force Hospital, Jorhat, Assam, and health camps at various places in Assam like Miryani, Mohanbari, Tezpur, Missamari.

Study included 500 apparently healthy ladies 21-65 years of age from northeast origin and from rest of India in study duration of 18 months.

Rest of India population is families of defence personnel living in Jorhat and nearby areas. Families of defence personnel are a heterogeneous group of population from all over India representing mini India.

\section{Sample Size}

Sample size calculated on basis of awareness among women of Tripura [11] done in 2015.

Using formula $\frac{4 \mathrm{XPXQ}}{L^{2}}$

$(15.57 \%=15 \%)$

$\mathrm{Q}=100-P$

$L=$ absolute error $=5 \%$

Sample size $=204$

For more authenticity minimum sample of 500 was taken

Inclusion Criteria were married lady in age between 21 and 65 years.

Exclusion Criteria were ladies with post total hysterectomy and who were already detected with premalignant lesion of cervix.

Written informed consent about the study was taken following which questionnaire was given. It consists of 25 questions which include details of personal particular, questions regarding the presence of any risk factors for cervical cancer in them, knowledge about cervical cancer and awareness about Pap smear and their attitude towards Pap smear.

Following which health talk with the help of charts and power point presentations was given which include details about cervical cancer and Pap smear.

Women who were already undergone Pap smear at least once were encouraged to get it done again if she is under that time duration, while remaining women were encouraged to undergo Pap smear test. 
Samples were preserved and send to pathologist in 5 Air Force Hospital, reporting was done using Bethesda classification.

Results were analysis statistically.

\section{Data Analysis}

The data were entered into Microsoft excel 2010 and Master Chart was prepared. Data analysis was done using SPSS version-23 and PAST software. Statistical analysis of data among groups was carried out and presented as tables, pie charts and bar diagrams having numbers and percentages. To assess the awareness about knowledge, attitude and practice of Pap smear. Odds ratios with 95\% confidence interval were reported. The various statistical tests like Chi-square test, student- $t$ test, $z$-test were applied as appropriate for comparison of nominal data. $p$ value $<0.05$ was considered as statistically significant.

\section{Result and Discussion}

Out of 500 participants 213 participants were aware of cervical cancer and 118 participants were aware of Pap smear. Among 500 participants 417 underwent Pap smear.

In our study, $23.6 \%$ (118/500) of participants are aware of Pap smear out of which 95\% (113/118) say it is for early detection of cervical cancer. Time interval to repeat Pap smear in every 3 years is said by $53.4 \%$ (63/118) and best timing to do the test is 10th to 20th days of menstrual cycle said by $38 \%$ (45/118). However, scoring of knowledge suggests only $22.88 \%$ (27/118) is having adequate knowledge, i.e. they have given correct answer to all the three questions.

Study shows that awareness about Pap smear is statistically significant in occupation, awareness is more in participants doing some job like nurses, ward shahyika etc. (Table 1).

Knowledge about Pap smear is statistically significant in married participants more than 35 years of age (Table 2). Participants who were aware of Pap smear (118) and undergone Pap smear themselves are statistically significant with $p$ value of 0.0001 suggesting the significance of awareness and adequate knowledge about performance of Pap smear towards the attitude and practise of it (Table 3).

To determine specificity of Pap smear, various risk factors which shows statistically significant variation with abnormal Pap smears are long duration of marriage, multiple pregnancy, low family income and menstrual irregularities (Table 4).

After introduction of Pap smear technology in 1940s, it has evolved rapidly through different reporting methods into presently well-established Bethesda system of reporting. Bethesda system recognizes both squamous and glandular cytologic abnormalities. The squamous cell abnormalities include atypical squamous cell ASC which are divided into two groups-one of undetermined significance (ASCUS) and other cannot exclude high-grade squamous intraepithelial lesions (ASCUS-H); low-grade squamous intraepithelial lesion (LSIL) which correlates with histologic CIN 1, high-grade squamous intraepithelial lesion (HSIL) which correlates with histologic CIN2, CIN3 and carcinoma in situ. Glandular cell abnormalities suggestive of adenocarcinoma are atypical glandular cell (AGC) endocervical, endometrial, or not otherwise specified, AGCs-favouring neoplastic, endocervical non-specific, endocervical adenocarcinoma in situ (AIS) and adenocarcinoma. Two methods of cytology screening presently available are - the conventional and the liquidbased cytology. There is no significant difference in detecting cervical cytological abnormality except that added advantage of HPV testing for further guide in management in the liquid base procedure. Usefulness of polymerase chain reaction (PCR) for detection of high-risk subtypes of HPV has further enhanced the detection of early cervical abnormalities thus can reduce the risk of cervical dysplasia and cancer at subsequent evaluation by $40 \%$ [12].

In 2012, American Society for Colposcopy and Cervical Pathology (ASCCP) and the American Society for clinical pathology issued joint screening guidelines for different surviellence strategies and options based on age, screening history, risk factors and choice of screening tests [13]. The recommendations for women of average risk are:-

- Screening should begin at 21 years of age. Women aged 21-29 years should receive cytology every 3 years. HPV testing should not be performed in this age group (although it can be used to follow-up a diagnosis of ASCUS). Regardless of age of sexual initiation, women below 21 years need not be screened.

- Age from 30 to 65 years preferred approach is to screen every 5 years with contesting-both HPV and cytology.

- Women with post total hysterectomy status for noncancerous lesion need not undergo screening.

- Annual screening by any method is not recommended.

- In spite of positive HPV-vaccinated status in women the screening should be followed as per schedule.

Utility of Pap smear test for detection of other gynaecological lesions such as infection, inflammation, irradiation induced changes occasional malignancy from endometrium and ovary has been observed. Conventional cytology yields sensitivity of $30-40 \%$ in detection of endometrial cancer [14]. The liquid-based cytology 
Table 1 Awareness about Pap smear with socio demographic data

\begin{tabular}{|c|c|c|c|c|c|}
\hline \multirow[t]{2}{*}{ Variables } & \multicolumn{5}{|c|}{ Awareness of Pap smear } \\
\hline & Yes & No & Odds ratio/CI & Chi-square & $p$ value \\
\hline \multicolumn{6}{|l|}{ 1. Region } \\
\hline Northeast & 41 & 150 & $0.8235(0.5352,1.267)$ & 0.78 & 0.3772 \\
\hline Rest of India & 77 & 232 & & & \\
\hline \multicolumn{6}{|l|}{ 2. Age } \\
\hline$<=35$ years & 75 & 247 & $0.9533(0.6204,1.465)$ & 0.048 & 0.827 \\
\hline$>35$ years & 43 & 135 & & & \\
\hline \multicolumn{6}{|l|}{ 3. Marital status } \\
\hline Married & 115 & 376 & $0.6117(0.1506,2.484)$ & 0.482 & 0.488 \\
\hline Others & 3 & 6 & & & \\
\hline \multicolumn{6}{|l|}{ 4. Occupation } \\
\hline Housewife & 71 & 298 & $0.12744(0.0722,0.225)$ & 78.1 & $0.001 *$ \\
\hline Service & 43 & 23 & & & \\
\hline Others $(R)$ & 04 & 61 & & & \\
\hline \multicolumn{6}{|l|}{ 5. Education level } \\
\hline Illiterate & 08 & 44 & $0.67532(0.284,1.528)$ & 5.13 & 0.077 \\
\hline Up to 12 th standard & 49 & 182 & & & \\
\hline Graduate and above $(R)$ & 61 & 156 & & & \\
\hline \multicolumn{6}{|l|}{ 6. Religion } \\
\hline Hindu & 102 & 346 & $0.66329(0.3536,1.2444)$ & 1.65 & 0.198 \\
\hline Others & 16 & 36 & & & \\
\hline
\end{tabular}

*High positive association

\begin{tabular}{|c|c|c|c|c|c|}
\hline \multirow[t]{2}{*}{ Variables } & \multicolumn{5}{|c|}{ Knowledge of Pap smear } \\
\hline & Adequate & Inadequate & Odds ratio $(95 \% \mathrm{CI})$ & Chi-square & $p$ value \\
\hline \multicolumn{6}{|l|}{ 1. Region } \\
\hline Northeast & 13 & 33 & $0.61273(0.2573-1.459)$ & 1.1067 & 0.26842 \\
\hline Rest of India & 14 & 58 & & & \\
\hline \multicolumn{6}{|l|}{ 2. Age } \\
\hline$\leq 35$ years & 08 & 62 & $0.19694(0.0772-0.5024)$ & 3.401 & $0.00067^{*}$ \\
\hline$>35$ years & 19 & 29 & & & \\
\hline \multicolumn{6}{|l|}{ 3. Marital status } \\
\hline Married & 27 & 88 & - & 7.9948 & $0.01956^{*}$ \\
\hline Others & 00 & 03 & & & \\
\hline \multicolumn{6}{|l|}{ 4. Occupation } \\
\hline Housewife & 15 & 56 & $0.69196(0.2879-1.663)$ & 0.82131 & 0.41043 \\
\hline Service & 12 & 31 & & & \\
\hline Others $(R)$ & 00 & 04 & & & \\
\hline \multicolumn{6}{|l|}{ 5. Education level } \\
\hline Illiterate & 00 & 08 & 0.66365 & 0.97741 & 0.37665 \\
\hline Up to 12 th standard & 10 & 39 & & & \\
\hline Graduate and above $(R)$ & 17 & 44 & & & \\
\hline \multicolumn{6}{|l|}{ 6. Religion } \\
\hline Hindu & 24 & 78 & $1.333(0.3505-5.073)$ & 0.4219 & 0.67303 \\
\hline Others $(R)$ & 03 & 13 & & & \\
\hline
\end{tabular}

*Statistically significant 
Table 3 To assess attitude and practice of Pap smear (118 participants)

\begin{tabular}{lllll}
\hline Variable & Yes & No & Chi-square & $p$ value \\
\hline Pap smear ever done & 69 & 49 & 17.537 & $0.0001^{*}$ \\
Recommended Pap smear to other & 37 & 81 & & \\
\hline
\end{tabular}

*High positive association

Table 4 To assess specificity of Pap smear

\begin{tabular}{|c|c|c|c|c|c|c|c|}
\hline Result/variable & Normal & Infection & Inflammatory & ASCUS & LSIL & HSIL* & Cancer cervix* \\
\hline \multicolumn{8}{|l|}{ 1. Age at marriage } \\
\hline$<21$ years & 208 & 11 & 07 & 08 & 29 & 02 & 01 \\
\hline 21 years or $>$ & 105 & 13 & 00 & 19 & 14 & 00 & 00 \\
\hline$p$ value & $<0.0001 *$ & 0.1441 & $0.0043^{*}$ & $0.0343 *$ & 0.222 & & \\
\hline \multicolumn{8}{|l|}{ 2. Duration of marriage } \\
\hline$<10$ years & 174 & 17 & 00 & 05 & 09 & 00 & 00 \\
\hline $10-25$ years & 121 & 07 & 04 & 22 & 31 & 00 & 00 \\
\hline$>25$ years & 18 & 00 & 03 & 00 & 03 & 02 & 01 \\
\hline$p$ value & $<0.0001 *$ & $0.0001 *$ & $0.0639 *$ & $0.0001 *$ & $0.001 *$ & & \\
\hline \multicolumn{8}{|l|}{ 3. No of pregnancies } \\
\hline Up to 3 & 302 & 24 & 01 & 26 & 39 & 00 & 00 \\
\hline More than 3 & 11 & 00 & 06 & 01 & 04 & 02 & 01 \\
\hline$p$ value & $<0.0001 *$ & $0.0001 *$ & $0.0219 *$ & $0.0001 *$ & $0.001^{*}$ & & \\
\hline \multicolumn{8}{|l|}{ 4. Family income } \\
\hline$<\operatorname{Rs} 25 \mathrm{k}$ & 10 & 02 & 00 & 00 & 05 & 01 & 00 \\
\hline Rs $25-35 \mathrm{k}$ & 108 & 12 & 05 & 17 & 21 & 01 & 01 \\
\hline More than $35 \mathrm{k}$ & 195 & 10 & 02 & 10 & 17 & 00 & 00 \\
\hline$p$ value & $<0.0001 *$ & $0.0302 *$ & $0.0235^{*}$ & $0.0003 *$ & $0.0075^{*}$ & & \\
\hline \multicolumn{8}{|l|}{ 5. Family h/o cancer } \\
\hline Yes & 12 & 04 & 00 & 05 & 10 & 01 & 00 \\
\hline No & 301 & 20 & 07 & 22 & 33 & 01 & 01 \\
\hline$p$ value & $<0.0001 *$ & $0.0001 *$ & $0.0203 *$ & $0.0011 *$ & $0.0005^{*}$ & & \\
\hline \multicolumn{8}{|l|}{ 6. Use of contraceptives } \\
\hline Yes & 167 & 12 & 02 & 11 & 15 & 00 & 00 \\
\hline No & 146 & 12 & 05 & 16 & 28 & 02 & 01 \\
\hline$p$ value & 0.2352 & - & 0.126 & 0.3359 & $0.0474 *$ & & \\
\hline \multicolumn{8}{|l|}{ 7. Personal habits } \\
\hline No habits & 298 & 24 & 06 & 20 & 27 & 00 & 01 \\
\hline Use of tobacco etc. & 15 & 00 & 01 & 07 & 16 & 02 & 00 \\
\hline$p$ value & $<0.0001 *$ & $0.0001 *$ & 0.1256 & $0.0124 *$ & 0.094 & & \\
\hline \multicolumn{8}{|l|}{ 8. Menstrual problem } \\
\hline Yes & 151 & 19 & 03 & 13 & 32 & 02 & 01 \\
\hline No & 162 & 05 & 04 & 14 & 11 & 00 & 00 \\
\hline$p$ value & 0.5341 & $0.0043 *$ & 0.445 & $0.0371 *$ & $0.0014 *$ & & \\
\hline
\end{tabular}

*Due to less number $p$ value cannot be calculated

screening provides slightly better result [15]. Detection of the psammoma bodies in a Pap smear may be associated with ovarian cancer [16]. However, detection of the ovarian cancer by cervical cytology is low only of $15 \%$ sensitivity is reported [17]. By utilising molecular assay technique, Kinde and colleagues generated a list of 12 genes that represent common mutations in endometrial and ovarian cancers [18.] This multiplexed molecular assay termed "Papgene" included 12 genes: APC, AKT1, BRAF, CTNNB1, EGFR, FBXW7, KRAS, NRAS, PIK3CA, 
PPP2R1A, PTEN and TP53. Specific PCR probes with attached unique identifiers were designed to regions of these genes and used to amplify DNA collected from liquid-based Pap sample. These amplicons, representing normal and mutated targets, were sequenced in mass with latest sequencing technology. Pap samples from patients with known endometrial and ovarian cancers were evaluated and mutations were identified at rates as low as $0.01 \%$ mutant copies; in contrast no mutation was observed in samples from patients without cancer. These exploratory studies may usher the foundation of a new genomic-based screening test for screening for gynaecological malignancies.

\section{Conclusion}

Among 500 participants, $42.6 \%$ are aware of cervical cancer and $23.6 \%$ are aware of Pap smear.

Among participants who are aware of Pap smear main source of information is health persons (88\%). Participants who are doing some job or service have statistically significant awareness. Adequate knowledge is in $22.8 \%$. It is statistically significant in married women age more than 35 years of age.

As only 58\% (69/118) among participants who are aware of Pap smear, ever done Pap smear and only $31 \%$ (37/118) ever recommended Pap smear to others, suggesting attitude towards practice of Pap smear is better compared to other studies. However, attitude towards recommending Pap smear to others is poor. With more awareness about cervical cancer it can be increased.

With motivation knowledge, lectures about cervical cancer and Pap smear to all the participants 83.4\% (417/ 500) underwent Pap smear, suggesting that with availability of proper resources and sharing of knowledge about cervical cancer attitude towards screening can be improved.

\section{Recommendation}

Women should be encouraged to take responsibility of their own health and actively take part in various screening programme.

Poor attitude towards practise of Pap smear can be improved by addressing the inhibition factors such as painful procedure, absence of symptoms.

Areas of risk factors for cervical cancer need to be addressed by health personnel. Encourage people to marry above age of 21 years, encourage use of contraceptives and limit family size to two children.
Although health personnel is the main source of information, repeated mobile health camps need to be conducted. This will help in covering wider population and spreading knowledge.

Mass media (television, radio, newspaper) can be involved for repeated emphasis on routine screening for cervical cancer as part of cervical cancer screening programme.

\section{Compliance with Ethical Statement}

Conflict of interest There are no areas of conflict of interest in the study.

Ethical Statement Institutional ethical and scientific committee clearance has been taken.

Open Access This article is distributed under the terms of the Creative Commons Attribution 4.0 International License (http://creative commons.org/licenses/by/4.0/), which permits unrestricted use, distribution, and reproduction in any medium, provided you give appropriate credit to the original author(s) and the source, provide a link to the Creative Commons license, and indicate if changes were made.

\section{References}

1. WHO Cervical Cancer estimated incidence, mortality, and prevalence worldwide 2012.

2. Goldie SJ, Gaffikin L, Goldhaber-Fiebert JD, Gordillo-Tobar A, Levin C, Mahe C, et al. Alliance for cervical cancer prevention cost working group. Cost-effectiveness of cervical cancer screening in five developing countries. $N$ Engl $J$ Med. 2005;353:2158-68.

3. Nor HO, Matejka R. Challenges to cervical cancer screening in a developing country: the case of Malaysia. Asia Pacific J Cancer Prev. 2009;10:747-52.

4. WHO. World health survey. Geneva: WHO; 2003.

5. Gakidou E, Nordhagen S, Obermeyer Z. Coverage of cervical cancer screening in 57 countries: low average levels and large inequalities. PloS Med. 2008;5:e132.

6. ICO Information centre on HPV and Cancer (Summary Report 2014/08/22). Human Papilloma and Related disease in India 2016.

7. National Centre for Disease Informatics Research. National cancer registry programme, ICMR three year report of population base registries, 2009-2011. Bangalore: NCDIR-NCRP (ICMR); 2014.

8. Eileen MB. Human papilloma virus and carcinoma cervix. Clin Microbiol Res. 2003;16(1):1-17.

9. Biswas LN, Manna B, Maiti PK, Sengupta S. Sexual risk factors for cervical cancer among rural Indian women. A case control study. Int J Epidemiol. 1997;26(3):491-5.

10. U.S. Preventive Service Task Force. Cervical Cancer Screening, March 2012. https://www.uspreventiveservicetaskforce.org.

11. ICMR. Three year report of population based cancer registries 2006-2008, National Cancer Registry Programme. New Delhi: ICMR; 2010. 
12. Naucler $P$, et al. Human papillomavirus and Papanicolaou tests to screen for cervical cancer. N Engl J Med. 2007;18(357):1589.

13. Saslow D, Solomon D, Lawson HW, et al. American Cancer Society, American society for colposcopy and Cervical Pathology, and American Society for clinical Pathology screening guidelines for the prevention and early detection of cervical cancer. CA Cancer J Clin. 2012;62:147-72.

14. Sams SB, Currens HS, Raab SS. Liquid-based Papanicolaou tests in endometrial carcinoma diagnosis. Performance, error root cause analysis, and quality improvement. Am J Clin Pathol. 2012;137:248.
15. Schorge JO, Hossein Saboorian M, Hynan L, Ashfaq R. ThinPrep detection of cervical and endometrial adenocarcinoma: a retrospective cohort study. Cancer. 2002;25(96):338.

16. Kern SB. Prevalence of psammoma bodies in Papanicolaoustained cervicovaginal smears. Acta Cytol. 1991;35:81.

17. Takashina $\mathrm{T}$, et al. Cervicovaginal and endometrial cytology in ovarian cancer. Acta Cytol. 1988;32:159.

18. Shannon N, Westin Gordon BM, Andrea PM. Repurposing the pap smear: one step closer to gynecologic cancer screening. Sci Transl Med. 2013;5(167):167ps1. 